\title{
Factors of Virtual Classroom to Enhance Online Learning in Multicultural Society for Pre-Service Teacher Students
}

\author{
Ophat Kaosaiyaporn, Wasant Atisabda, Jirawan Plodkaew, and Jatuporn Promrak, Member, IACSIT
}

\begin{abstract}
This study aimed to analyze factors of virtual classroom to enhance online learning in multicultural society for pre-service teacher students. The sample consisted of 237 administrators, instructors and students who were teaching and studying at Faculty of Education Prince of Songkla University and the study was divided into two phases: The first phase was to analyze and synthesize literature and documents relating to the development of a virtual classroom for distance education for undergraduate teacher students and the second phase was to analyze factors for a virtual classroom for distance Education for pre-service teacher students. The research findings indicated that the virtual classroom for distance education for pre-service teacher students consisted of eight factors: 1) Factor of virtual classroom system, 2) Factor of element of virtual classroom, 3) Factor of virtual classroom management, 4) Factor of learning activities and knowledge management on virtual classroom, 5) Factor of learning experiences management, 6) Factor of virtual classroom development, 7) Factor of supporting to seft-directed learning system, and 8) Factor of knowledge creation and knowledge reflection.
\end{abstract}

Index Terms-Virtual classroom, online learning, teacher education, multicultural education, pre-service teacher education, educational technology in higher education.

\section{INTRODUCTION}

In the knowledge-based society, new skills for pre-service teachers are required to serve the professional practices; those are reflection, inquiry, technology-use, and knowledge construction [1]. The new learning environment is created for developing new teachers in the new society; those included student-centered approach, knowledge- centered approach, community-centered approach, and assessment-centered approach [2]. The new teacher in the new society is not the one who teaches, but takes an important role to design, facilitate, and empower learning to students. In addition, in the new society we need to prepare our new teachers to appreciate the cultural diversity in the multicultural society. So educators must not overlook the fact that Thailand is a multicultural society and a multicultural approach is the only form appropriate to the development of students from all cultural groups. Hence the need to study Multicultural Education [3], [4].

Distance education has widespread for decades. Many technology innovations have been developed to deliver the

Manuscript received April 20, 2014; revised June 24, 2014. This work was supported in part by Prince of Songkla University.

The authors are with the Department of Educational Technology, Faculty of Education, Prince of Songkla University, Thailand (e-mail: ophat.k@psu.ac.th, vassan.a@psu.ac.th, plodkaew28@gmail.com, tang_35343@hotmail.com). knowledge and experiences to learners with least limitation. The virtual classroom is one approach applied for the new learning environment. It can be used for classroom supported media as well as the distance learning environment. The most important characteristic of virtual classroom is to be used in the classroom without requiring laboratory [5]. The virtual classroom has the good potential for controlled performance assessment within an ecologically valid environment and appears to parse out significant effects due to the presence of distraction stimuli.

The researchers aimed to develop the factors to improve the new learning environment for teaching and learning in teacher education by using the technology innovation of virtual classroom. These factors are the significant factors prepare the new teachers and to strengthen the professional practices, leading to the knowledge-based society, living in the multicultural society and the coming ASEAN Economic Community (AEC).

\section{PURPoses OF THE STUdy}

This study was to analyze factors of virtual classroom to enhance online learning in multicultural society for preservice teacher students at Faculty of Education, Prince of Songkla University.

\section{RESEARCH METHODOLOGY}

The research method consisted of two phases.

Phase I - Analyzing and synthesizing related literature and documents regarding the virtual classroom enhancing online learning in multicultural society for pre-service teacher students.

The researcher analyzed and synthesized the concepts, principles, theories, and research on technology innovation and multicultural education in teacher education.

Phase II - Analyze factor analysis of the virtual classroom enhancing the online learning in multicultural society for pre-service teacher students. The research results indicated that a virtual classroom enhancing the online learning in multicultural society for pre-service teacher students. This phase has two stages.

1) Create Variable Factors for a virtual classroom enhancing the online learning in multicultural society model in three areas including;

- Online learning activities

- Distance education in cultural diversity and multicultural education

- cVirtual classroom based on the experts' opinion on the 
appropriate components and processes (variables) pertaining to a virtual classroom to enhance online learning activities in multicultural society.

Seek expert opinions about suitable components and processes (Variables) pertaining to a virtual classroom enhancing online learning in multicultural society for pre-service teacher students. as follows:

- Create a table allowing experts to analyze and rate each variable.

- Assess the expert responses in this table.

- Use the information obtained from the experts' opinions phase to develop the questionnaire..

- Assess the quality of the questionnaire for reliability by content validity and a pilot study using the alpha coefficient (Cronbach)

2) To analyze the factors using factor analysis with the principal component analysis. The researchers selected the subjects in the faculty members and undergraduate teacher students to develop a variable at factor loading of .50 or higher. A factor should include at least three variables to be considered as the factor.

\section{RESEARCH FINDINGS}

1) The samples consisted of 237 administrators, instructors and undergraduate teacher students who teach and study at Faculty of Education, Prince of Songkla University, Thailand.

2) The factor analysis revealed as follows:

- Hypothesis testing in correlation matrix method by Bartlett's test of Sphericity was significantly at the low level $(\mathrm{sig}=.0000)$.

- Analysis and comparison of Bartlett's Test of Sphericity size by using KMO (The Kaiser-Meyer-Olkin) or measure of sampling adequacy were found at .934 which means the data was closed to 1 indicate that were more suitable for analysis. [6]-[7]

3) The analysis of factors for a virtual classroom to enhance online activities in multicultural society for undergraduate teacher students implemented the principal component analysis technique. The result revealed that a model had eight factors with 59.542 percentage of variance.

4) This analysis was based on Orthogonal rotation by varimax method with factor loading of .50 or higher lead to eight factors with thirty seven variables as follows:

- Factor one: virtual classroom system - they are eight variables with weight of $.687-.520$.

a) The system with the facilities for the system administrator and the instructors for the course control and management to deliver the online distance learning,

b) The system with record and monitor facilities for the user's performance,

c) Manual with explanation in Thai and illustration,

d) The system allows the system administrator to run the website management,

e) The module can be improved and added up and also report in multiple languages, f) Statistical records and analysis of tests' responses,

g) Virtual Classroom System with display in multi-language, including Thai language,

h) Variety of test format, e.g. multiple choice, multiple responses, true \& false, essay, etc.

- Factor two: element of virtual classroom - They are nine variables with weight of $.729-.527$.

a) Statistical system to track students' activities and to monitor learning participation in virtual classroom.

b) A good security system for virtual classroom.

c) Integration with Open Educational Resources.

d) E-mail as a tool for students to communicate with others.

e) Webboard as a tool for students to communicate and create an online community.

f) Summative and formative evaluation.

g) Contents on virtual classroom including text, picture, sound, video and multimedia.

h) Virtual classroom equipped with both contents and social network in classroom.

i) Learners' achievement record facility to support teacher planning and management of class activities and student achievement analysis.

- Factor three: virtual classroom management - they seven variables with weight of $.678-.520$.

a) The instructional system includes variety of tools to support communication between learners and instructor,

b) The curriculum management can support unlimited users and lessons,

c) The cloud computing is integrated with the virtual classroom to facilitate instructional process and increase efficiency of the system,

d) The instructor can create instructional resource or content through variety of functions and the connection with the external websites,

e) The lesson development system can support text-based instruction as well as streaming media,

f) The data management system includes the file and folder management to support the limited area for the instructor and learner to save information,

g) The curriculum management system includes 3 levels: learner, instructor, and system administrator anywhere anytime,

- Factor four: learning activities and knowledge management on virtual classroom - they are three variables with weight of $.652-.566$.

a) New learning environment with variety of platforms.,

b) Tools for managing communication and instructional activities in class,

c) Tools for creating the instructional interaction for class participants.

- Factor five: learning experiences management - they are three variables with weight of $.724-.615$.

a) Self-directed learning support,

b) Authentic learning support,

c) Active learning with more learning less time,

- Factor six: virtual classroom development - they are two variables with weight of $.521-.513$.

a) Improvement of the virtual classroom information 
system to connect with the PSU-Passport system,

b) Continuous update the capacity of virtual classroom system

- Factor seven: the self-directed learning system - they are two variables with weight of $.737-.583$.

a) The project-based learning approach as platform for interactive learning on virtual classroom,

b) The co-operative learning approach as platform for interactive learning on virtual classroom, c) The problem-based learning approach as platform for interactive learning on virtual classroom.

- Factor eight: knowledge creation and knowledge reflection - they are two variables with weight of .637 -.514 .

a) 4.8.1 Continuous 24-hour service anywhere anytime,

b) 4.8.2 Learners' reflection tools to support instructional process.

More details of factor loading show in Table I.

TABLE I: FACTOR LOADING DETAIL

\begin{tabular}{|c|c|c|}
\hline Variables & Text & Factor loading \\
\hline & Factor one & \\
\hline 45 & $\begin{array}{l}\text { - The system with the facilities for the system administrator and the instructors for the course } \\
\text { control and management to deliver the online distance learning. }\end{array}$ & .687 \\
\hline 46 & - The system with record and monitor facilities for the user's performance. & .676 \\
\hline 40 & - Manual with explanation in Thai and illustration. & .659 \\
\hline 47 & - The system allows the system administrator to run the website management. & .642 \\
\hline 48 & - The module can be improved and added up and also report in multiple languages. & .640 \\
\hline 44 & - Statistical records and analysis of tests' responses. & .621 \\
\hline 37 & - Virtual Classroom System with display in multi-language, including Thai language. & .530 \\
\hline 42 & $\begin{array}{l}\text { - Variety of test format, e.g. multiple choice, multiple responses, true } \& \text { false, essay, etc. } \\
\text { Factor two }\end{array}$ & .520 \\
\hline 13 & $\begin{array}{l}\text { - Statistical system to } \\
\text { track students' activities and to monitor learning participation in virtual classroom. }\end{array}$ & .729 \\
\hline 12 & - A good security system for virtual classroom. & .695 \\
\hline 29 & - Integration with Open Educational Resources & .689 \\
\hline 15 & - e-Mail as a tool for students to communicate with others. & .651 \\
\hline 16 & - Webboard as a tool for students to communicate and create an online community. & .598 \\
\hline 14 & - Summative and formative evaluation. & .576 \\
\hline 21 & - Contents on virtual classroom including text, picture, sound, video and multimedia. & .556 \\
\hline 17 & - Virtual classroom equipped with both contents and social network in classroom. & .533 \\
\hline 23 & $\begin{array}{l}\text { - Learners' achievement record facility to support teacher planning and management of class } \\
\text { activities and student achievement analysis. } \\
\text { Factor three }\end{array}$ & .527 \\
\hline 35 & $\begin{array}{l}\text { - The instructional system includes variety of tools to support communication between learners } \\
\text { and instructor. }\end{array}$ & .678 \\
\hline 33 & - The curriculum management can support unlimited users and lessons. & .637 \\
\hline 28 & $\begin{array}{l}\text { - The cloud computing is integrated with the virtual classroom to facilitate instructional process } \\
\text { and increase efficiency of the system. }\end{array}$ & 636 \\
\hline 38 & $\begin{array}{l}\text { - The instructor can create instructional resource or content through variety of functions and the } \\
\text { connection with the external websites. }\end{array}$ & .572 \\
\hline 34 & - The lesson development system can support text-based instruction as well as streaming media. & .544 \\
\hline 36 & $\begin{array}{l}\text { - The data management system includes the file and folder management to support the limited area } \\
\text { for the instructor and learner to save information. }\end{array}$ & .540 \\
\hline 32 & $\begin{array}{l}\text { - The curriculum management system includes } 3 \text { levels: learner, instructor, and system } \\
\text { administrator anywhere anytime. } \\
\text { Factor four }\end{array}$ & .520 \\
\hline
\end{tabular}




\begin{tabular}{|c|c|c|}
\hline Variables & Text & Factor loading \\
\hline 27 & - New learning environment with variety of platforms. & .652 \\
\hline 26 & - Tools for managing communication and instructional activities in class. & .632 \\
\hline 25 & $\begin{array}{l}\text { - Tools for creating the instructional interaction for class participants. } \\
\text { Factor five }\end{array}$ & .566 \\
\hline 6 & - Self-directed learning support. & .724 \\
\hline 7 & - Authentic learning support. & .673 \\
\hline 5 & $\begin{array}{l}\text { - Active learning with more learning less time. } \\
\underline{\text { Factor six }}\end{array}$ & .615 \\
\hline 18 & $\begin{array}{l}\text { - Improvement of the virtual classroom information system to connect with the PSU-Passport } \\
\text { system. }\end{array}$ & .521 \\
\hline 49 & $\begin{array}{l}\text { - Continuous update the capacity of virtual classroom system. } \\
\text { Factor seven }\end{array}$ & .513 \\
\hline 3 & - The project-based learning approach as platform for interactive learning on virtual classroom. & .737 \\
\hline 4 & - The co-operative learning approach as platform for interactive learning on virtual classroom. & .653 \\
\hline 2 & $\begin{array}{l}\text { - The problem-based learning approach as platform for interactive learning on virtual classroom. } \\
\text { Factor eight }\end{array}$ & .583 \\
\hline 1 & - Continuous 24-hour service anywhere anytime. & .637 \\
\hline 31 & - Learners' reflection tools to support instructional process. & .514 \\
\hline
\end{tabular}

\section{CONCLUSION}

In conclusion, the results of this study revealed that the Factors could be grouped into 8 sets as follows:

Factor one: the virtual classroom system is designed to support the efficiency of the system, e.g. the course management system for the system administrator and instructor, the multiple language support for future use in foreign language instruction, variety of test and evaluation format including test score management, the students' learning progress report in order to trace their activities, and the system can added up and modernized to support future use.

Factor two: the element of virtual classroom includes the security system, the users' records and statistical records, and the instructional evaluation system. In addition, the communication tools, e.g. e-mail, webboard, chatroom, reflective tools to record their learning progress. The content will be presented through audio, video, multimedia, and the application of Open Educational Resources (OER) in the virtual classroom.

Factor three: the virtual classroom management is assigned for 3 levels: student, instructor, and system administrator who can make unlimited access to the system anywhere anytime. The lesson include text-based presentation and streaming media. The cloud storage can be applied for the lesson, including the external links.

Factor four: Factor of learning activities and knowledge management on virtual classroom was a factor that focused on the new learning environment and instructional activities used in the virtual classroom. It should support the diverse learning styles as well as the community of practices and scholars.

Factor five: Factor of learning experiences management was a factor that focused to teacher should design and develop the challenged course for students to create their knowledge by including both cooperative and communicative learning activities. The students could clearly explain what they have learned from task and problem learning activities. Moreover, The awareness of cultural diversity should be included in the virtual classroom activities. Teacher should assign to students to create and asset their knowledge on e-Portfolio.

Factor six: the virtual classroom development will be updated to keep up with technology change to make more learning less time. The portfolio system will be developed for learners to record the learning progress.

Factor seven: the self-directed learning system is designed to create the new learning environment for instructional interaction in the virtual classroom, co-operative learning and problem-based learning approach are integrated in learning process which can encourage students to apply the prior and new knowledge to the real life experiences.

Factor eight: knowledge creation and knowledge reflection is designed to record new knowledge emerged during the learning process, including the reflective journal, blog, etc.

\section{RECOMMENDATIONS}

\section{A. Recommendations for the Research Application}

The Factors are flexible and can be modified to proper situation, students, subjects and objectives of learners.

\section{B. Recommendations for the Next Research}

1) Make the Factors more complete, research and develop the learning facilities to encourage both synchronous and asynchronous online learning activities,

2) Develop the Factors to cover the basic education which is an early preparation for teachers and students in being 
the member of ASEAN Economic Community.

\section{REFERENCES}

[1] W. Atisabda, "Technology integration in teacher education," $J$. of Education, vol. 15, no. 1, pp. 342-348, 2003.

[2] M. Riel. (2000). New design for connected teaching and learning. [Online]. Available: http://www.gse.uci.edu/mriel/whitepaper/index.html

[3] K. Ophat, K. Jintavee, and N. Jaitip, "Factors of virtual networks for multicultural classrooms to enhance knowledge construction and cultural awareness for graduate students" Technical Education Journal King Mongkut's University of Technology North Bangkok, vol. 3, no. 1, pp. 48-56, 2012.

[4] Y. Banyat. (2008). The encouragement a children development in the context of cultural diversity. [Online]. Available: http://www.cf.mahidol.ac.th/autopage/file/WedJuly2008-22-18-5-4art icel-004.pdf

[5] V. Aslim-Yetis, "Virtual classroom site in French written expression lesson: a practice sample," Procedia - Social and Behavioral Sciences., vol. 2, no. 2, pp. 466-470, 2010.

[6] J. F. Hair, R. E. Anderson, R. L. Tatham, and W. C. Black, Multivariate Data Analysis, 5th ed., New Jersey: Prentice, 1998.

[7] W. Nongluk, Lisrel model: Statistical methods for research, 3rd ed., Bangkok: Chulalongkorn University, 1999.

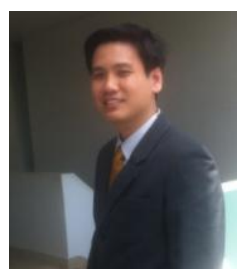

Ophat Kaosaiyaporn was born in Narathiwat, Thailand. He received a bachelor of education in the field of art education and master of education in the field of educational technology and communications from Prince of Songkla University, Thailand, and a doctor of philosophy of educational communications and technology from Chulalongkorn University, Thailand. $\mathrm{He}$ is a lecturer at the Department of
Educational Technology, Faculty of Education, Prince of Songkla University, Thailand.

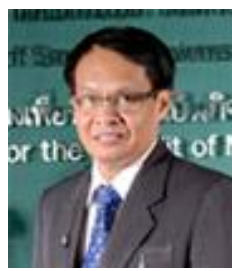

Wasant Atisabda is an assistant professor at the Department of Educational Technology, Faculty of Education, Prince of Songkla University, Thailand. $\mathrm{He}$ received a bachelor of education in the field of teaching german as the second language and master of education in field of audio-visual education from Chulalongkorn University, Thailand, and a doctor of philosophy of Higher and Continuing Educationfrom University of Missouri, USA.

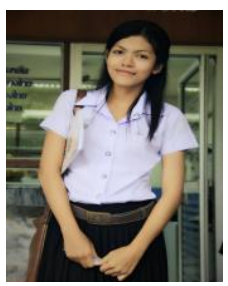

Jirawan Plodkaew was born in Nakhon $\mathrm{Si}$ Thammarat, Thailand. She received a bachelor of education in the field of educational technology and communications from Prince of Songkla University, Thailand. She is a researcher at Department of Educational Technology, Faculty of Education, Prince of Songkla University, Thailand.

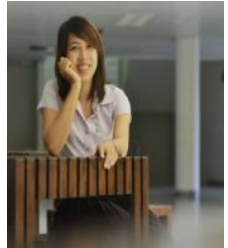

Jatuporn Promrak was born in Songkhla, Thailand. She received a bachelor of education in the field of educational technology and communications from Prince of Songkla University, Thailand. She is a researcher at the Department of Educational Technology, Faculty of Education, Prince of Songkla University, Thailand. 